\title{
Narrativas orais: formas e funções
}

Michael Hanke*

\section{RESUMO}

Esta contribuição discute as narrativas orais como uma espécie de comunicação cotidiana, abordadas sob duas perspectivas complementares: as formas e as funções. A análise formal trata a estruturação da sintaxe narrativa, segundo a tradição inaugurada pela análise estrutural de Labov/ Waletzky. O aspecto funcional trata também a função argumentativa (St. Toulmin), estabelecida entre a própria narrativa e a inserção na conversação. O recorte empírico é composto por narrativas orais de sonhos, já tratado em outros textos, na perspectiva da análise do discurso.

\section{ABSTRACT}

In this article, I analyze oral narratives as a form of everyday communication that can be analysed under two complementary perspectives: its forms and functions. The formal analysis deals with the arrangement of narrative syntax in conformity to the tradiction initiated by Labov/ Waletzky structural analysis. The funcional aspect deals also with the argumentative function (St. Toulmin) instituted between the narrative itself and its insertion into the conversaton. The empirical indentation is composed by oral narratives of dreams, already observed in other texts, under the viewpoint of discourse's analysis.

*Professor da UFMG. 


\section{Introdução}

Embora não exista uma definição, consensualmente aceita na ciência, para o termo "narrativa", fica claro que narrar é uma forma básica de atividade lingüística. É um tipo próprio da comunicação cotidiana ou, segundo Wittgenstein, um “jogo de linguagem” (PU 23). Mesmo Aristóteles já considerava que a narrativa é uma dentre as formas (schemata) de linguagem. ${ }^{1}$ A habilidade de narrar, sendo específica do ser humano ${ }^{2}$ e sua inteligência, é parte integrante da sua competência lingüística e simbólica. ${ }^{3}$

Como produto arcaico da cultura humana, as narrativas servem, dentre outras funções básicas, para acumulação, armazenamento e transmissão de conhecimentos. Segundo o psicólogo Jerome Bruner (1991), as narrativas servem como meio de percepção e a nossa realidade é resultado de uma construção narrativa. Narrar contribui para a estruturação da experiência humana, pois "organizamos nossa experiência e nossa memória principalmente através da narrativa" (Bruner 1991, 14, 21). A partir das narrativas são construídas teorias sobre a realidade (Ochs et al. 1992), e, sendo assim, elas servem como "ponto de fuga através do qual torna-se possível a apreensão do cotidiano" (Mendonça et al. 2001, 9). Elas são meios de sociabilidade, pois através delas as experiências individuais são comunicadas e tornadas "públicas" ou socialmente conhecidas. Uma vez que uma narrativa é sempre proferida e fabricada por alguém, vista de longe esta pode parecer uma atividade monológica. Mas nesse jogo lingüístico sempre participam também os ouvintes e a construção de uma narrativa precisa da cooperação destes, e, como não há narrativa sem narrador e sem ouvinte (Barthes 1988, 125), a narrativa verbal é construída dialogicamente, num discurso.

\section{Formas}

Uma narrativa é mais freqüentemente caracterizada como um ato de linguagem que faz referência a uma série de ações ou acontecimentos situados no passado, sejam esses reais ou ficcionais. ${ }^{4}$ Labov/Waletzky definem narrativa como um método para recapitular experiências passadas, capaz de estabelecer uma relação entre uma série de sentenças e uma série de acontecimentos. A narrativa faz uso da possibilidade de representação simbólica da linguagem e representa algo passado em termos de tempo e ausente em termos de espaço. Assim, ela transcende tempo e espaço, como uma referência a algo que não está presente no momento ou como representação de algo imaginado (Swearingen 1990, 181).

Então a narrativa tem dois níveis: o ato de fala (em inglês: "story") e a referência aos acontecimentos, aos objetos e às circunstâncias (em inglês: "history"). Através do "story", que conta e seleciona os detalhes relevantes, a "history" se torna acessível. 
Com relação à natureza dos elementos obrigatórios numa narrativa não há um consenso entre os teóricos. A estrutura básica, obviamente, é composta por início, meio e fim; e, segundo Chafe $(1990,94)$, uma narrativa precisa de uma introdução, de um momento (quando?), um local (onde?), personagens atuantes (quem?) e uma situação de fundo ("background activity"), no qual o conteúdo da narrativa se desenvolve. Este conteúdo deve ser constituído por uma série de eventos conectados que foram realizados ou experienciados pelos sujeitos (Bal 1985, 8). Para Labov/Waletzky, a exigência mínima para se caracterizar uma narrativa é uma ligação temporal entre pelo menos duas sentenças.

Apesar da dificuldade de se caracterizar uma narrativa cotidiana a partir de elementos obrigatórios, estas podem ser identificadas facilmente por causa da sua natureza dialógica, ou seja, a inserção num discurso. Para iniciar uma narrativa, o narrador precisa saber se os seus ouvintes estão interessados e dispostos a ouvi-la. Assim ele tem que sinalizar que ele quer produzir isto e "pedir permissão" para fazê-lo. Uma vez que aceitam, os ouvintes têm obrigações (mostrar interesse, não interromper, rir no momento certo ou reagir adequadamente, etc.), como também o narrador tem obrigações tais como terminar a narrativa corretamente, esclarecer partes que precisam informações suplementares, etc. No final da narrativa, o pacto sobre essas obrigações é anulado e as regras do discurso não-narrativo reinstaladas. Sendo assim, é indispensável uma sinalização de que a narrativa chegou ao fim. Uma vez identificadas através das marcações de início e fim, as narrativas podem ser isoladas como partes de um discurso e, assim segmentadas, terem a sua estrutura analisada.

\section{A análise formal da sintaxe narrativa}

A análise formal da estruturação da sintaxe narrativa foi inaugurada por Labov/Waletzky (1967), que através de uma análise estrutural, deram início à pesquisa linguística na área de narrativa conversacional e orientaram trabalhos posteriores nessa area. ${ }^{5}$

Segundo Labov/Waletzky, produtos da tradição literária ou verbal têm estruturas narrativas, que só podem ser analisadas segundo a sua função no contexto de origem. Essas estruturas fundamentais podem ser encontradas em versões verbais de experiências pessoais, em narrações cotidianas de pessoas comuns. A partir destas - e não nos produtos de alto nível da literatura - eles desenvolveram um sistema para analisar narrações cotidianas.

Labov/Waletzky estabeleceram distinções entre as propriedades formais e funcionais. Propriedades formais são estruturas típicas, que podem ser encontradas tanto no nível de sentenças como também na narrativa como um todo, e permitem compreender a estrutura interna das narrativas. A análise funcional destaca que, uma série de elementos colocados numa ordem 
temporária ainda não constituem uma narrativa, mas apenas uma descrição. Para que seja constituída uma narrativa, é necessaria uma função, ou seja, um motivo pelo qual ela é contada, um interesse de ordem pessoal. Enquanto as propriedades formais correspondem ao nível de referência dos acontecimentos, as propriedades funcionais correspondem à avaliação pessoal do narrador, seus interesses e seus motivos. Essa é também a perspectiva de Astington, Feldman, Bruner et al. ${ }^{6}$ segundo a qual uma narrativa é constituída de dois planos: um plano de ação, que contém o nível referencial, e um plano de consciência, no qual está presente o conhecimento, o pensamento e o sentimento, tanto daqueles que participam quanto daqueles que protagonizam a narrativa.

Uma narrativa completa tem, segundo Labov/Waletzky, os seguintes elementos estruturais:

1. A síntese ("abstract", do que se trata?), que resume a narrativa e indica qual a natureza do seu conteúdo; por exemplo7: "Trata-se em geral da questão de se procurar um banheiro e encontro grandes dificuldades em achar um. Esse sonho é muito mais complexo, mas eu consigo me lembrar muito bem dele. Estava ..."

2. A orientação ("orientation", quem? quando? o quê? onde?), que dá referências do local, hora, da cena e das pessoas envolvidas; exemplo: "Ontem eu sonhei que minha mãe mudou-se para Paris, e eu arrumei um apartamento para ela lá num prédio velho e alto, no qual eu subi pelo elevador ....".

3. O episódio inesperado ("complication", o que aconteceu?), exemplo: "Estava andando de bicicleta, e o meu nenê estava na cesta da bicicleta. De algum modo ele caiu, e eu o perdi. Mas não me lembro como ... de repente eu percebo que ele está em cima de um muro amarrado e eu estou embaixo na rua gritando: "Não precisa chorar, eu vou pegar você".

4. A avaliação ("evaluation”. qual reação?), que está ligada ao foco central. Numa outra contribuição (1972), Labov aprofunda o conceito de avaliação, classificando tipos diferentes. A avaliação deixa de ser um gesto isolado, feito num instante exato e único da narrativa, para estar presente de forma contínua e diversificada no desenrolar da narrativa. Exemplo: "A noite passada (ha!ha!ha!) depois do meu casamento na igreja (ha!ha!ha!) eu estava dentro do carro e (ha!ha!ha!) eu vi que no lugar das latinhas amarradas no párachoque (ha!ha!ha!) tinha um ciclista (rir)".

Enquanto o texto sublinhado é articulado acompanhado de risos ("ha!ha!ha!") e corresponde à avaliação contínua no desenrolar da narrativa; o "rir" final, que sucede a fala, corresponde à avaliação feita num exato instante. Este último não compõe a fala, mas compõe a narrativa.

5.Uma solução ou um resultado ("result", qual o desfecho?). No sonho sobre uma visita a Paris, a protagonista enfrenta várias aventuras: o elevador serve como avião, ela sobrevoa a paisagem, consegue pilotá-lo como um 
carro, supera vários obstáculos como, por exemplo, a fiação elétrica, e finalmente: "Voltei para o prédio, entrei, apertei o "cinco", subi até minha mãe, deixei o elevador, estava no quinto andar, e comentei com minha mãe: "Não usa o elevador, de jeito nenhum!" Assim, eu acordei. Era bem estranho. Também engraçado."

Todos esses elementos podem ser entendidos como respostas para as perguntas correspondentes e constituem a estruturação da sintaxe narrativa.

\section{A função argumentativa}

Além das várias funções já mencionadas, as narrativas podem servir como argumentos (McGuire 1990, 231). Devido à sua estruturação sintática, a narrativa tem uma coerência lógica interna, a qual estabelece uma relação entre as suas partes constitutivas.

Por ser uma forma de comunicação cotidiana, a narrativa sempre faz parte de um discurso falado, o que implica uma situação concreta de narrar "hic et nunc", quer dizer, um momento definido, uma situação, circunstâncias espaçotemporais. Parte da situação é constituída pelos parceiros da comunicação e pelo tema do discurso. Essa conexão temática do discurso e as suas contribuições, ou seja, a rede temática, está relacionada à coesão argumentativa e ao papel argumentativo da narrativa. Como ato lingüístico, a narrativa é construída tendo em vista todos esses parâmetros (situação, parceiros, rede temática/argumentativa etc.), e no modo como esses são percebidos pelo narrador. Assim, a estrutura interna da narrativa está conectada ao discurso como um todo.

A comunicação tem, em geral, um caráter argumentativo; até uma fala trivial, como parte de um discurso, tem uma conexão argumentativa, pois ela pode se tornar objeto de uma justificativa ("por que você falou isso?"). Sendo ação, ela implica uma intencionalidade. A narrativa como ação (lingüística) também desempenha uma função em relação a essa intenção. Assim, aplicando uma abordagem mais abrangente da argumentação, cada contribuição para um discurso ou fala está numa relação argumentativa, como foi mostrado por Toulmin (1958, 109-111). Para o autor cada argumentação tem os seguintes elementos: uma exposição (dado, “datum”, D), uma conclusão (C), uma modalidade (ou força) de dedução entre exposição e conclusão (modality, Q) e uma regra ou "licença de inferir" (razão, "warrant", W).8 Este último (W) está novamente baseado em evidências diferentes ("backing", B), e vale se não for objeto da regra de excessão (R).

Esse esquema pode ser aplicado para a estrutura interna da narrativa assim como para a própria narrativa e a inserção desta na conversação. Dentro da narrativa, uma frase anterior pode funcionar como exposição para uma frase posterior e para a conclusão. Se por exemplo uma síntese anuncia "alguma coisa interessante" ou "engraçada", os passos seguintes têm que 
cumprir essa anunciação e apresentar um conteúdo apropriado. Caso contrário, poderá ser cobrada a modalidade: “por que contou, se não é engraçado?".

Assim como as narrativas, a organização do discurso é um procedimento lógico que usa de argumentos (Petrilli 1991, 142). Narrativas têm um caráter argumentativo: se contadas como exemplos, elas desempenham uma função de criar evidências ou uma licença de inferir para uma exposição ou um complexo de exposição-conclusão. Assim, se conclusões são tiradas a partir delas, elas servem como dado ou exposição.

As três formas da inferência lógica, segundo Peirce, a indução, dedução e abdução, são relevantes devido a sua universalidade, uma vez que estão presentes em qualquer tipo de pensamento, podendo ser encontradas tanto na lógica científica quanto na comunicação cotidiana, e portanto, nas narrativas cotidianas. Conseqüentemente, elas são também essenciais para a estrutura da argumentação, pois elas constituem a modalidade (ou força) de dedução entre a exposição e a conclusão. Aplicando essas três formas ao corpus dessa pesquisa, constituído por 113 narrativas de sonhos, encontramse as seguintes classes:

1. Num primeiro padrão temos no início um argumento, muitas vezes acompanhado de uma declaração pessoal, seguido pela narrativa e uma finalização com o mesmo argumento inicial. Trata se do padrão dedutivo, pois o argumento é colocado em primeiro lugar e a narrativa assume uma posição dedutiva em relação a ele. Um caso (a narrativa) está subordinado a um argumento; a narrativa evidencia o argumento e é entendida de acordo com o sentido que o argumento oferece. $\mathrm{O}$ argumento inicial pode ser proferido por outro participante do discurso, o que evidencia o caráter dialógico da ação narrativa.

2. Num segundo padrão a narrativa funciona como ponto de partida inicial, do qual algo é derivado. Aqui a narrativa serve comodado (ou exposição), da qual conclusões são tiradas.

A diferença entre esse padrão e o anterior (dedutivo), é que aqui não há uma argumentação anterior, mas esta é desenvolvida a partir da narrativa. Por isso, esse padrão é caraterizado comoindutivo. Os argumentos desenvolvidos são inéditos, pois não foram introduzidos antes da narrativa.

3. O terceiro padrão estabelece uma conexão entre a narrativa e os discursos anterior e posterior a ela, através de uma semelhança hipotética, a qual é transformada numa relevância temática ao longo do discurso. Esse padrão é abdutivo no sentido de que algo é introduzido como supostamente (e verdadeiramente) relevante, e cuja relevância (que pode variar de intensidade) é evidenciada apenas depois. 


\section{Bibliografia:}

ARISTÓTELES. Die Poetik. Stuttgart 1982.

ASTINGTON, Janet. Narrative and the Child's Theory of Mind. In: Britton/ Pellegrini 1990: 151-171.

BAL, Mieke. Narratology: Introduction to the Theory of Narrative. Toronto 1985.

BARTHES, Roland. Einführung in die strukturale Analyse von Erzählungen. In: (idem) Das semiologische Abenteuer. Frankfurt/Main 1988: 102-143.

BONHEIM, Helmut. Theory of Narrative Modes. In: Semiotica 14, 1975: 329344.

BRITTON, Bruce/PELLEGRINI, A. D. (orgs.). Narrative Thought and Narrative Language. Hillsdale, N.J. 1990.

BRUNER, Jerome. The Narrative Construction of Reality. In: Criti-cal Inquiry 18, 1991: 1-21.

CABRAL, Isabel Cristina M./MINCHILLO, Carlos Alberto C.. A Narração. São Paulo 1997.

CHAFE, Wallace. Some things that narratives tell us about the mind. In: BRITTON/PELLEGRINI, 1990: 79-98.

DE SOUZA, Wander Emediato. Retórica, Argumentação e Discurso. In: MARI, H. et al. (orgs.) 2001: 157-177.

ENLICH, Konrad (org.). Erzählen im Alltag. Frankfurt/Main 1980.

ENLICH, Konrad (org.). Diskursanalyse in Europa. Frankfurt/Main 1994.

FELDMAN, Carol/ BRUNER, Jerome/ RENDERER, Bobbi e SPITZER, Sally. Narrative Comprehension. In: BRITTON/PELLEGRINI,1990: 1-78.

FISHER, Walter. Narration as a Human Communication Paradigm: the case of public moral argument. In: Communication Monographs 51, 1984: 1-22. FISHER, Walter. The Narrative Paradigm: an elaboration. In: Communication Monographs 52, 1985: 347-367.

GÜLICH, Elisabeth/QUASTHOFF, Uta. Narrative Analysis. In: VAN DIJK, Teun A. (org.): Handbook of Discourse Analysis, Vol. 2, London 1985: 169197.

GUMBRECHT, Hans Ulrich. Erzählen in der Literatur/Erzählen im Alltag. In: EHLICH (org.) 1980: 403-419.

HANKE, Michael. Träumer, Traum und Adressat - Traumdar-stellungen in Alltags kommunikation. In: Siegener Periodicum zur Internationalen Empirischen Literaturwissenschaft 7, 1988: 163-178.

HANKE, Michael (org.). Traumerzählungen in Gesprächen. Beiträge zu einer Her-meneutischen Konferenz. Tübingen 1992 (Special Issue Kodikas-/Code 15, H. 3/4).

HANKE, Michael. Schemata und Makrostrukturen alltagsweltlicher Traumerzäh-lungen. In: HANKE (org.) 1992: 279-288. 
HANKE, Michael. Narratives and argumentation. Some conversational operations connecting narratives to discourse. In: Frans H. van Eemeren, Rob Grootendorst, J. Anthony Blair e Charles A. Willard (orgs.): Proceedings of the Third ISSA Conference on Argumentation (University of Amsterdam, June 21-24, 1994). Vol. III: Reconstruction and Application. Amsterdam 1995: 251-260.

HANKE, Michael. Erzählend konstruieren. In: Hans Rudi Fischer/Siegfried J. Schmidt (orgs.) Wirklichkeit und Welterzeugung. In memoriam Nelson Goodman. Heidelberg 2000: 373-382.

HANKE, Michael: Kommunikation und Erzählung. Zur narrativen Vergemeinschaftungspra-xis am Beispiel konversationellen Traumerzählens. Würzburg 2001.

JÖNSSON, Linda/LINELL, Per. Story Generations: From dialogical interviews to written reports in police interrogations. In: Text 11, 1991:419440.

LABOV, William. The Transformation of Experience in Narrative Syntax. In (Labov, org.): Language in the inner city. Studies in the Black English Vernacu-lar. Philadelphia 1972: 354-396.

LABOV, William/WALETZKY, Joshua: Narrative Analysis: oral versions of personal experience. In: J. Helm (org.): Essays on the Verbal and Visual Arts. Seattle 1967: 12-44.

LINELL, Per/JÖNSSON, Linda. Suspect Stories: perspective setting in an asymmetrical situation. In: Marková, I./Foppa, K. (org.): Asymmetries in Dialogue. Hemel Hempstead 1991: 75-100.

LACARIELLO, Joan. Canonicality and Consciousness in Child Narrative. In: Britton/Pellegrini 1990: 131-149.

MARI, Hugo/MACHADO, Ida Lúcia/ DE MELLO, Renato (orgs.). Análise do Discurso. Fundamentos e Práticas. Belo Horizonte 2001.

MCGUIRE, Michael. The Rhetoric of Narrative: A hermeneutic, critical theory. In: Britton/Pellegrini 1990: 219-236.

MENDONÇA, Carlos Camargos/ GUIMARÂES, César/ VAZ, Paulo Bernardo/ DA SILVA, Regina Helena/ FRANÇA, Vera Regina Veiga. Narrativas do Cotidiano: proposições para um Projeto de Pesquisa Integrado. Em: GERAES. Estudos em Comunicação e Sociabilidade 52, 2001: 4-13.

NERBONNE, John. Reference Time and Time in Narration. In: Linguistics and Philosophy 9, 1986: 83-95.

OCHS, Elinor/TAYLOR, Carolin. Family Narrative as a Political Activity. In: Discourse and Society 3, 1992: 301-340.

OCHS, Elinor/TAYLOR, Carolin/RUDOLPH, D./SMITH, R. (1992). Storytelling as a Theory-Building Activity. In: Discourse Processes 15, 1992: 37-72.

PEIRCE, Charles S.. Collected Papers. Vol. I-VIII. Cambridge, Mass. 1960seg. 
Petrilli, Susan: For a Semiotic Narration of Semiotics. In: Semiotica 87, 1991: 119-146.

POLANYI, Livia. Linguistic and Social Constraints on Storytelling. In: Journal of Pragmatics 6, 1982: 509-524.

POLANYI, Livia. Conversational Storytelling. In: van Dijk, Teun A. (org.): Handbook of Discourse Analysis, Vol. 3, London 1985: 183-201.

STUBBS, Michael. Discourse Analysis. The sociolinguistic analysis of natural language. Oxford 1983.

SWEARINGEN, C. Jan. The Narration of Dialogue and Narration within Dialogue: The transition from story to logic. In: Britton/Pellegrini 1990: 173197.

TOULMIN, Stephen. The Uses of Argument. Cambridge 1958.

WITTGENSTEIN, Ludwig. Philosophische Untersuchungen. Frankfurt/Main 1984.

UNGEHEUER, Gerold. Kommunikationstheoretische Schriften. I: Kommunikationstheorie II: Symbolische Erkenntnis und Kommunikation. Aachen 1987, 1990.

\section{Notas:}

1 As outras formas são o imperativo, o requerimento, a pergunta e a resposta (Poetica 1456b9-13).

2 Fisher $(1984,1985)$ desenvolve o conceito de "homo narrans".

3 Cf. Gülich/Quasthoff $(1985,169)$, segundo os quais "storytelling is a general human semiotic skill".

4 Cf. por exemplo Cabral/Minchillo (1997, 1), segundo as quais narrar "é fazer um relato de determinada seqüência de acontecimentos, reais ou inventados". 5 Linell/Jönsson (1991, 86), Stubbs $(1983,213)$.

6 Cf. Astington 1990, 152seg., Feldman, Bruner et al. 1990, 2seg.

7 O recorte empírico é composto por narrativas orais de sonhos, já tratado em outros textos, na perspectiva da análise do discurso (Hanke 1995, 2000, 2001). 8 Segundo a apresentação do esquema de Toulimin que De Souza faz, a "licença de inferir" contem "os enunciados implícitos que justificam as [sic] conclusão" (2001, 168). 


\section{Palavras- chave}

1. Análise de Discurso

2. Narrativas

3. Formas sintáticas

4. Funções argumentativas

CONTRACAMPO 